\title{
The expression of heat shock proteins 27 and 105 in squamous cell carcinoma of the tongue and relationship with clinicopathological index
}

\author{
Nooshin Mohtasham ', Shahab Babakoohi ${ }^{2,3}$, Laleh Montaser-Kouhsari ${ }^{2,3}$, Bahram Memar ${ }^{4}$, Jahanshah \\ Salehinejad ${ }^{1}$, Amin Rahpeyma ${ }^{5}$, Saeedeh Khageh-Ahmady ${ }^{1}$, Parviz Marouzi ${ }^{6}$, Alireza Firooz ${ }^{2}$, Hamidreza \\ Pazoki-Toroudi $^{2}$, Kazem Anvari ${ }^{7}$
}

\author{
${ }^{1}$ DDS, Oral \& Maxillofacial Pathology Department, Dental Research Center, Faculty of Dentistry, Mashhad University of \\ Medical Sciences \\ ${ }^{2} \mathrm{MD}$, PhD Center for Research and Training in Skin Diseases and Leprosy, Tehran University of Medical Sciences, Tehran, Iran \\ ${ }^{3}$ MD, Dermatopathology Department, Razi hospital, Tehran University of Medical Sciences, Tehran, Iran \\ ${ }^{4}$ MD, Department of Pathology, Imam Reza hospital, Mashhad University of Medical Sciences, Mashhad, Iran \\ ${ }^{5}$ DDS, Oral \& Maxillofacial Surgery Department, Dental Research Center, Faculty of Dentistry Mashhad University of medical \\ sciences, Mashhad, Iran \\ ${ }^{6}$ M.FC, Biostatistics department, Mashhad University of Medical Sciences, Mashhad, Iran \\ ${ }^{7} \mathrm{MD}$, Assistant professor of Radiation Oncology Oncology Research Center \& Department, Omid Hospital , Mashhad Univer- \\ sity of Medical Sciences, Mashhad, Iran
}

Correspondence:

Omid Hospital-Alandash Square,

Koohsangi Avenue,

Mashhad-Iran

shahabmdt@gmail.com
Mohtasham N, Babakoohi S, Montaser-Kouhsari L, Memar B, Salehinejad J, Rahpeyma A, Khageh-Ahmady S, Marouzi P, Firooz A, Pazoki-Toroudi $\mathrm{H}$, Anvari K. The expression of heat shock proteins 27 and 105 in squamous cell carcinoma of the tongue and relationship with clinicopathological index. Med Oral Patol Oral Cir Bucal. 2011 Sep 1;16 (6):e730-5. http://www.medicinaoral.com/medoralfree01/v16i6/medoralv16i6p730.pdf



\begin{abstract}
Introduction: In oral cavity, the tongue is the most common site prone to development of squamous cell carcinoma (SCC). Considering malignant transformation as a cellular stress, the expression of heat shock proteins (HSPs) may be affected in this process. In this study we assessed the expression of HSP105 and HSP27 as two of the most interested stress proteins and investigated their relationship with grade and stage of the tongue SCC.

Material and Methods: Fifty-six specimens including 31 early and 25 advanced tongue SCC were gathered. All specimens were graded histologically from I to III. Sixteen sections of normal oral mucosa were used as control group. The cellularity and intensity of HSP105 and HSP27 expression were studied immunohistochemically in both case and control groups. Results were expressed by histochemical score (HSCORE).

Results: Significant differences were observed between expression of HSPs and stage of the disease. From early to advanced stage, the expression of HSP105 and HSP27 increased and decreased, respectively. There was no relationship between histological grade of lesion and HSCORE of HSP105 expression ( $\mathrm{P}=0.5)$, although, HSP27 expression had reverse relationship with the SCC histological grade.

Conclusion: HSP27 and HSP105 may be indicated for prognostic purposes in evaluation of tongue SCC. HSP 27 may be used for more accurate microscopic grading of tongue SCC. Increased expression of HSP105 in advanced stage may lead to using this protein for immunotherapy of tongue SCC.
\end{abstract}

Key words: Heat shock protein 27, Heat shock protein 105, tongue squamous cell carcinoma. 


\section{Introduction}

Squamous cell carcinoma (SCC) composes ninety-four percent of oral cavity carcinomas (1). Tongue cancer is the most common SCC of oral cavity with more tendency for local invasion and spread (2).

General consensus states that accumulation of several genetic abnormalities in cells is required for malignant transformation (3). In current era of molecular pathology; a myriad of oncogens including Ras, myc, c-erbB1; antiapoptotic proteins such as Bcl-x and Bcl-2; and several tumor suppressor genes, the most eminent of them, P53, have been recognized in pathogenesis of oral carcinomas. However, the exact cause and effect mechanisms of them have not yet been fully elucidated (4).Another group of proteins involved in malignant transformation are Heat Shock Proteins (HSPs). These proteins as of the most abundant intracellular substances are produced in response to different stresses including hyperthermia, heavy metals, oxygen free radicals, infections, inflammation and ischemia (2-4).HSPs act as chaperones which protect unfolded or mal-folded proteins from destruction (5) and conduct them toward organelles to help in repairing mal-folded proteins .If this cascade is not efficient, they mark the abnormal proteins for destruction in proteosome complex (6) and if defective proteins accumulate, HSPs induce apoptosis for rapid elimination of these abnormal structures (7). HSPs can revive lost proteins by resynthesis and refolding denatured proteins (8) or other intracellular reactions (9).

Recent discovery of the HSP family on the surface of malignant cells has led to proposing HSPs as tumoral antigens or carriers of such antigens $(10,11)$.

HSP105, a high molecular weight mammalian stress protein belonging to HSP110 family, is released in response to wide range of stress factors like heat, infection, ischemia, and tumors $(12,13)$.

It has two $\alpha$ and $\beta$ isoforms, former is produced in both physiologic and pathologic conditions but latter, is exclusively constructed during heat stress (14).

HSP105 is normally bound to P53 in cytoplasm and inhibits P53 induced apoptosis. Heat stimulates HSP105 to separate from P53 and its transportation to the nucleus leading to apoptosis (15).

HSP27 is a low molecular weight protein which contributes to heat tolerance and other cellular functions including signal transduction, differentiation, proliferation, and cellular movement (16). It is involved in keratinocyte differentiation and epidermis development (17) and works as chaperone for keratinization. This cytoplasmic marker is present in granular and spinosum layers of normal epidermis (18).

The association of HSP27 Overexpression and survival rate of non-small cell lung cancer patients has been demonstrated (19). In skin cancers, squamous cell carcinoma (SCC) which is more aggressive and has more propensity to develop metastasis than basal cell carcinoma (BCC) expresses HSP 105 marker much more intense than BCC (20), on the other hand HSP 27 is not expressed in SCC which is attributed to its aggressive nature (4).

HSPs have become a target of interest for cancer immunotherapy. Immunization of some murine tumors by autologus HSPs has slowed the tumor progression and reduced metastasis rate (21). This study aimed at determining the correlation between the expression of HSP 105 and HSP 27 and their relationship with grade and stage in tongue SCC. The findings, when supported by other studies may be of prognostic and therapeutic value. This is the first study performed on HSP 105 in tongue SCC and its correlation with clinicopathologic indices. Here, mean number of the cells positive for HSP 105 and HSP 27 along with their intensity of expression in epithelial cells are obtained using immunohistochemistry (IHC); In addition, these two properties are merged by expressing them as histochemical score (HSCORE) for each grade and stage.

\section{Material and Methods}

In this retrospective study, we collected profile records along with pathology blocks of patients with tongue SCC referred to a teaching hospital in Mashhad, Iran from September 1994 to May 2009. Treatment protocol for patients with SCC of tongue was surgery and modified radical neck dissection and adjuvant radiotherapy if needed. Patients underwent tumor surgery without cervical lymph node dissection and patients who received neoadjuvant treatment were excluded from the study due to uncertainty about the stage of the disease. Therefore some cases were excluded due to the fact that some physicians in few years ago did not consider modified radical neck dissection in stage I tumors. Moreover, specimens with low quality, inappropriate fixation, or necrotic or bloody areas were also excluded.

Thirty-one patients were in early stages (I and II) and 25 patients were in advanced stage (III) and 16 patients were healthy controls. Stages of the tumor were classified according to the TNM system. Histological grading (I, II and III) was according to WHO classification (22).The study protocol was approved by the Ethical Committee of the Faculty of Dentistry.

Mean number of HSP 27 and HSP 105 positive cells and their intensity of expression in epithelial cells were investigated by IHC.

Immunohistochemistry:

Four- $\mu \mathrm{m}$ serial sections from each formalin-fixed, paraffin-embedded blocks were cut. IHC was then performed on sections fixed on poly-L-lysine-coated glass slides. Deparaffinized and rehydrated slides were incubated for 30 minutes in 3\% $\mathrm{H} 2 \mathrm{O} 2 /$ methanol to stop endogenous peroxidase activity, and then irrigated with phosphate-buffered saline (PBS) for 20 minutes. Speci- 
mens were incubated with the primary anti-HSP27 monoclonal antibody (Catologue No. Clone 2B4; Novocastra Laboratories Ltd,Newcastle, U.K.) and primary anti-HSP27 monoclonal antibody (Catologue No. Clone 58 F12; Novocastra Laboratories Ltd,Newcastle, U.K.). The slides were incubated for one hour in room temperature. The sections were rinsed three times with PBS at room temperature. The secondary antibody was applied to treat immune complexes. Immune complexes were identified by streptavidin peroxidase (Novo Link Polymer detection system). After three times washing with PBS, the immunoreactivity was visualized by diaminobenzidine and hydrogen peroxide. The procedure was followed by counterstaining with hematoxylin and then slides examined by light microscopy. Epithelial cells were counted with light microscope at hot spot in five areas at 100X and 400X magnification. The areas were marked by highlighter pens to prevent counting one area twice. The density of stained cells for HSP105 and HSP 27 markers was recorded as: 0: negative or low staining, 1: distinct staining, 2: strong staining.

The mean HSCORE and the percent of Overexpression were applied to express the severity of malignancy. HSCORE was estimated as follows: HSCORE = Pi (i + 1), in which $\mathrm{Pi}$ (calculated percentage of stained tumor cells) ranged from 0 to $100 \%$ and intensity of stained epithelial cells (i) was 0,1 or 2 as mentioned above. Overexpression of HSP27 or HSP 105 was defined by the mean HSCORE of 100. Positive control cases were retrieved from normal testis tissue for HSP 105 and normal skin tissues for HSP 27.

The results were analyzed using Statistical Package of Social Sciences software version 16.0 (SPSS, Chicago, Ill). ). HSP 105 and HSP 27 expression and the intensity of their staining on epithelial cells were compared by nonparametric Mann-Whitney and Kruskal-Wallis as well as Fisher's exact tests. A P value less than 0.05 was considered statistically significant.

\section{Results}

The mean age of patients with histological grades I, II and III of SCC was $62 \pm 14.8,55.22 \pm 16.24$, and $60.17 \pm 16.19$ years, respectively. (Table 1) and (Table 2) illustrate the mean number of HSP 105 and HSP 27 positive cells, intensity of their expression in epithelial cells and evaluation their HSCORE and overexpression in specimens of SCC with various histological grading (I, II, III) and stage (early, advanced) and control group. There was no statistically significant relationship between age and histological grade. Differences between

Table 1. HSP105 expression profile in different grades and stages of tongue squamous cell carcinoma.

\begin{tabular}{|c|c|c|c|c|c|c|c|c|c|}
\hline & \multirow{2}{*}{$\begin{array}{c}\text { Mean } \\
\text { number of } \\
\text { HSP } 105 \\
\text { positive cells }\end{array}$} & \multirow{2}{*}{$P$ value } & \multicolumn{3}{|c|}{$\begin{array}{c}\text { Intensity of HSP105 expression in } \\
\text { epithelial cells (\%) }\end{array}$} & \multirow{2}{*}{$P$ value } & \multicolumn{2}{|c|}{$\begin{array}{l}\text { HSCORE for HSP105 } \\
\text { evaluation }\end{array}$} & \multirow{2}{*}{ P value } \\
\hline & & & - & + & ++ & & Mean & $\begin{array}{l}\text { Percent of Over } \\
\text { expression (\%) }\end{array}$ & \\
\hline Basal layer & 100 & \multirow{2}{*}{$\mathrm{P}<0.00$} & - & $18.7(\mathrm{n}=3)$ & $81.3(n=13)$ & \multirow{2}{*}{$\mathrm{P}=0.14$} & $281 \pm 40$ & 100 & \multirow[b]{2}{*}{$\mathrm{P}<0.00$} \\
\hline Spinusom layer & $20 \pm 15$ & & $25(n=4)$ & $18.7(\mathrm{n}=3)$ & $56.3(\mathrm{n}=9)$ & & $56 \pm 47$ & 25 & \\
\hline Grade I & $77 \pm 25$ & \multirow{3}{*}{$\mathrm{P}=0.25$} & - & $51.8(n=14)$ & $48.2(n=13)$ & \multirow{3}{*}{$\mathrm{P}=0.2$} & $197 \pm 83$ & 81.5 & \multirow{3}{*}{$\mathrm{P}=0.15$} \\
\hline Grade II & $73 \pm 32$ & & - & $33.3(\mathrm{n}=8)$ & $66.7(n=15)$ & & $201 \pm 103$ & 73.9 & \\
\hline Grade III & $96 \pm 5$ & & - & $14.3(\mathrm{n}=1)$ & $85.7(n=5)$ & & $275 \pm 48$ & 100 & \\
\hline Early stage & $62 \pm 28$ & \multirow{2}{*}{$\mathrm{P}<0.00$} & - & $67.7(\mathrm{n}=21)$ & $32.3(\mathrm{n}=10)$ & \multirow{2}{*}{$\mathrm{P}=0.01$} & $145 \pm 77$ & 64.5 & \multirow{2}{*}{$\mathrm{P}=0.00$} \\
\hline Advanced stage & $97 \pm 4$ & & - & $8(n=2)$ & $92(n=23)$ & & $283 \pm 28$ & 100 & \\
\hline
\end{tabular}

Table 2. HSP27 expression profile in different grades and stages of tongue squamous cell carcinoma.

\begin{tabular}{|c|c|c|c|c|c|c|c|c|c|}
\hline & \multirow{2}{*}{$\begin{array}{c}\text { Mean } \\
\text { number of } \\
\text { HSP } 27 \\
\text { positive cells } \\
\end{array}$} & \multirow{2}{*}{ P value } & \multicolumn{3}{|c|}{$\begin{array}{c}\text { Intensity of HSP27 expression in } \\
\text { epithelial cells (\%) }\end{array}$} & \multirow{2}{*}{ P value } & \multicolumn{2}{|c|}{$\begin{array}{c}\text { HSCORE for HSP27 } \\
\text { evaluation }\end{array}$} & \multirow{2}{*}{$P$ value } \\
\hline & & & - & + & ++ & & Mean & $\begin{array}{c}\text { Percent of Over } \\
\text { expression (\%) }\end{array}$ & \\
\hline Basal layer & $25 \pm 10$ & \multirow{2}{*}{$\mathrm{P}<0.001$} & $31.3(\mathrm{n}=5)$ & $25(\mathrm{n}=4)$ & $43.8(\mathrm{n}=7)$ & \multirow{2}{*}{$\mathrm{P}=0.1$} & $70 \pm 8$ & 25 & \multirow{2}{*}{$\mathrm{P}=0.01$} \\
\hline Spinusom layer & $84 \pm 25$ & & $6.3(\mathrm{n}=1)$ & $25(n=4)$ & $68.8(n=11)$ & & $231 \pm 86$ & 94 & \\
\hline Grade I & $90 \pm 12$ & \multirow{3}{*}{$\mathrm{P}=0.01$} & - & $37(n=10)$ & $63(n=17)$ & \multirow{3}{*}{$\mathrm{P}=0.4$} & $238 \pm 63$ & 100 & \multirow{3}{*}{$\mathrm{P}=0.03$} \\
\hline Grade II & $73 \pm 28$ & & - & $47.8(\mathrm{n}=11)$ & $52.2(\mathrm{n}=12)$ & & $196 \pm 101$ & 74 & \\
\hline Grade III & $60 \pm 28$ & & - & $33.3(n=4)$ & $66.7(\mathrm{n}=2)$ & & $143 \pm 86$ & 83.3 & \\
\hline Early stage & $96 \pm 6$ & \multirow{2}{*}{$\mathrm{P}<0.001$} & - & $9.7(n=3)$ & $90.3(n=28)$ & \multirow{2}{*}{$\mathrm{P}<0.001$} & $278 \pm 35$ & 100 & \multirow{2}{*}{$\mathrm{P}<0.001$} \\
\hline Advanced stage & $60 \pm 24$ & & - & $12(n=22)$ & $88(n=3)$ & & $128 \pm 53$ & 72 & \\
\hline
\end{tabular}


patients' age and tumor stages were remarkable $(\mathrm{P}=$ 0.02). There was no significant relation between sex and, histological grade and stage, HSCORE of HSP 27 and HSP 105. Histological views of the specimens studied by IHC are seen in (Figs. 1 to 3 ).



Fig. 1. HSP105 expression in advanced SCC, grade II, with 2nd degree staining intensity and $100 \%$ cellularity $(\times 100)$.



Fig. 2. HSP105 expression in early stage SCC, grade I, with 1nd degree staining intensity and $30 \%$ cellularity $(\times 100)$.

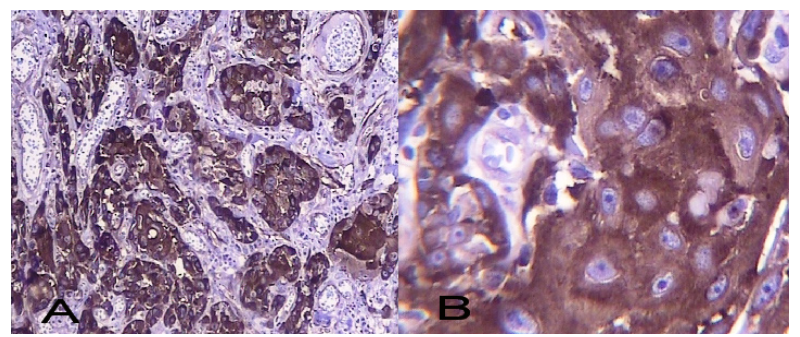

Fig. 3. Cytoplasmic HSP27 expression in early stage SCC, grade I, with 2 nd degree staining intensity and $100 \%$ cellularity (A: $\times 100$, B: $\times 400)$.

\section{Discussion}

The tongue is the most common site of oral cavity SCC. Its incidence has been increased two-fold among elder people whereas about five-fold in young people. The Determination of histological grade of SCC is to great extent a subjective issue depending on the assessment of pathologist and the location of biopsy (23).

To reach a more reliable conclusion we selected only tongue SCCs to prevent confounding of the results by using specimens from different parts of oral cavity.

The study of Muchemwa et al. (20) was the first report in which the expression of HSP105 was evaluated by means of HSCORE in skin cancers including 23 SCCs and 23 basal cell carcinomas. HSCORE $\geq 100$ was defined as Overexpression and $60 \%$ and $100 \%$ of primary and metastatic SCCs over expressed HSP105, respectively. By contrast, only $13 \%$ of basal cell carcinomas which are relatively benign slow growing tumors with low chance of metastasis showed such biologic behavior.

Suzuki et al. (6), studied expression of HSP27 in oral SCCs (30 well, 5 moderately and 2 poorly differentiated specimens as well as 5 normal control from oral mucosa). Staining intensity in tumoral cells increased from basal layer toward the surface which is compatible with our findings. In contrast to our results, there was no relationship between stage and grade of the tumors and HSP27 expression. This discrepancy is perhaps due to the large differences among the number of samples in different groups in that study.

Mese et al. (24) also did not find any relationship between stage and grade of the tumors and HSP27 expression; the confounding factor could be the selection of samples from different locations of oral cavity.

In another study, there was significant relationship between HSP27 expression with histological grade and clinical stage of oral SCCs but not with gender which both are in agreement with our findings (22). Also, Husseiny, et al. (25) suggested no relationship between stage and grade with gender.

Romanucci et al. (18) studied the expression of HSP27 in SCCs of skin and detected more expression of this marker in well differentiated SCCs compared with moderately differentiated specimens; Also, staining intensity for HSP27 was intensified in spinosum layer compared with basal layer. Similar to our findings, Fortin, et al. (26) showed weak expression of HSP27 in advanced stages of oropharyngeal carcinomas. Also, Kawanishi, et al. (27) investigated the expression of HSP 27 and HSP105 in 102 specimens of esophageal SCCs and recognized these two as valuable prognostic markers. They suggested that HSP27 is strongly associated with clinicopathologic characteristics and its expression is in reverse relationship with clinical stage which all agrees with our results. Above mentioned findings show 
a similarity between SCC behaviors in different tissues which necessitate more scrutiny on molecular biology of this malignancy which perhaps yields some key information applicable to a myriad of neoplasms.

On the other hand Nakajima, et al. (28) found no relationship between the rate of HSP27 expression and histological grading in esophageal SCCs which may lead us to conclude that tumors with identical pathology may express different biologic behaviors when emerge in different tissues, although in that study, the increased HSP expression had been associated with lymphocyte infiltration and consequently accelerated immune response. Moreover, that study concluded that reduction in HSP27 expression had been recognized as an indicative of tumor progression and stage rising. In practical view, immunization with HSP 105 extracted from bone marrow dendritic cells in mice with multiple experimentally created adenomas significantly reduced the number of small intestinal polyps which is promising for employing this protein in cancer immunotherapy (29).

Direct relationship of HSP105 and inverse relationship of HSP27 expression with stage of tongue SCC indicates their prognostic value. The high rate of HSP 27 expression in spinosum layer in control group (93.75\%) compared with basal layer suggests that HSP27 is a marker for keratinocyte differentiation. HSP 27 may be used for better histological grading of the tongue SCC. Progressive increase in HSP105 expression from normal oral mucosa toward advanced tongue SCC postulates the idea of association of this marker with the lesion stage and worse prognosis. Pursuant to this concept, HSP27 expression as a differentiation factor carries a better prognosis. Direct relationship between age and HSP105 expression in tongue SCC suggests that with higher ages the protein folding mechanism in keratinocyes is interrupted in affected patients. And last but not least, a statistically significant reverse relationship exists between HSP27 and HSP105 expression in tongue SCC.

Similar studies are encouraged for better understanding biologic behaviors of neoplasms which can potentially lead to development of novel curative techniques against them such as immunotherapy or recombinant DNA vaccines against different HSPs or other biological markers involved in neoplastic transformations.

\section{References}

References with links to Crossref - DOI

1. Pektas ZO, Keskin A, Günhan O, Karslioğlu Y. Evaluation of nuclear morphometry and DNA ploidy status for detection of malignant and premalignant oral lesions: quantitative cytologic assessment and review of methods for cytomorphometric measurements. J Oral Maxillofac Surg. 2006;64:628-35.

2. Wang A, Liu X, Sheng S, Ye H, Peng T, Shi F, et al. Dysregulation of heat shock protein 27 expression in oral tongue squamous cell carcinoma. BMC Cancer. 2009;9:167.

3. Trautinger F, Kindas-Mügge I, Dekrout B, Knobler RM, Metze D. Expression of the $27-\mathrm{kDa}$ heat shock protein in human epidermis and in epidermal neoplasms: an immunohistological study. Br J Dermatol. $1995 ; 133: 194-202$.
4. Lo Muzio L, Pannone G, Leonardi R, Staibano S, Mignogna MD, De Rosa G, et al. Survivin, a potential early predictor of tumor progression in the oral mucosa. J Dent Res. 2003;82:923-8.

5. Minton KW, Karmin P, Hahn GM, Minton AP. Nonspecific stabilization of stress-susceptible proteins by stress-resistant proteins: a model for the biological role of heat shock proteins. Proc Natl Acad Sci U S A. 1982;79:7107-11.

6. Suzuki H, Sugimura H, Hashimoto K. Overexpression of heat shock protein 27 is associated with good prognosis in the patient with oral squamous cell carcinoma. Br J Oral Maxillofac Surg. 2007;45:123-9.

7. Pelham HR. Speculations on the functions of the major heat shock and glucose-regulated proteins. Cell. 1986;46:959-61.

8. Gaitanaris GA, Papavassiliou AG, Rubock P, Silverstein SJ, Gottesman ME. Renaturation of denatured lambda repressor requires heat shock proteins. Cell. 1990;61:1013-20.

9. Zhu XL, Ohta Y, Jordan F, Inouye M. Pro-sequence of subtilisin can guide the refolding of denatured subtilisin in an intermolecular process. Nature. 1989;339:483-4.

10. Srivastava PK, Heike M. Tumor-specific immunogenicity of stress-induced proteins: convergence of two evolutionary pathways of antigen presentation? Semin Immunol. 1991;3:57-64.

11. Srivastava PK, DeLeo AB, Old LJ. Tumor rejection antigens of chemically induced sarcomas of inbred mice. Proc Natl Acad Sci U S A. 1986;83:3407-11.

12. Morris SD. Heat shock proteins and the skin. Clin Exp Dermatol. 2002;27:220-4.

13. Xue JH, Fukuyama H, Nonoguchi K, Kaneko Y, Kido T, Fukumoto $\mathrm{M}$, et al. Induction of Apg-1, a member of the heat shock protein 110 family, following transient forebrain ischemia in the rat brain. Biochem Biophys Res Commun. 1998;247:796-801.

14. Saito Y, Yamagishi N, Hatayama T. Different localization of Hsp105 family proteins in mammalian cells. Exp Cell Res. 2007;313:3707-17.

15. Kumagai J, Fukuda J, Kodama H, Murata M, Kawamura K, Itoh $\mathrm{H}$, et al. Germ cell-specific heat shock protein 105 binds to p53 in a temperature-sensitive manner in rat testis. Eur J Biochem. 2000;267:3073-8.

16. Pechan PM. Heat shock proteins and cell proliferation. FEBS Lett. 1991;280:1-4.

17. Gandour-Edwards R, McClaren M, Isseroff RR. Immunolocalization of low-molecular-weight stress protein HSP 27 in normal skin and common cutaneous lesions. Am J Dermatopathol. 1994;16:504-9.

18. Romanucci M, Bongiovanni L, Marruchella G, Marà M, di Guardo G, Preziosi R, et al. Heat shock proteins expression in canine intracutaneous cornifying epithelioma and squamous cell carcinoma. Vet Dermatol. 2005;16:108-16.

19. Malusecka E, Krzyzowska-Gruca S, Gawrychowski J, FiszerKierzkowska A, Kolosza Z, Krawczyk Z. Stress proteins HSP27 and HSP70i predict survival in non-small cell lung carcinoma. Anticancer Res. 2008;28:501-6.

20. Muchemwa FC, Nakatsura T, Ihn H, Kageshita T. Heat shock protein 105 is overexpressed in squamous cell carcinoma and extramammary Paget disease but not in basal cell carcinoma. Br J Dermatol. 2006;155:582-5.

21. Tamura Y, Peng P, Liu K, Daou M, Srivastava PK. Immunotherapy of tumors with autologous tumor-derived heat shock protein preparations. Science. 1997;278:117-20.

22. Lo Muzio L, Leonardi R, Mariggiò MA, Mignogna MD, Rubini C, Vinella A, et al. HSP 27 as posible prognostic factor in patients with oral squamous cell carcinoma. Histol Histopathol. 2004;19:119-28.

23. Ye H, Yu T, Temam S, Ziober BL, Wang J, Schwartz JL, et al. Transcriptomic dissection of tongue squamous cell carcinoma. BMC Genomics. 2008;9:69.

24. Mese H, Sasaki A, Nakayama S, Yoshioka N, Yoshihama Y, Kishimoto K, et al. Prognostic significance of heat shock protein 27 (HSP27) in patients with oral squamous cell carcinoma. Oncol Rep. 2002;9:341-4. 
25. El-Husseiny G, Kandil A, Jamshed A, Khafaga Y, Saleem M, Allam A, et al. Squamous cell carcinoma of the oral tongue: an analysis of prognostic factors. Br J Oral Maxillofac Surg. 2000;38:193-9.

26. Fortin A, Raybaud-Diogène H, Têtu B, Huot J, Blondeau L, Landry J. Markers of neck failure in oral cavity and oropharyngeal carcinomas treated with radiotherapy. Head Neck. 2001;23:87-93.

27. Kawanishi K, Shiozaki H, Doki Y, Sakita I, Inoue M, Yano M, et al. Prognostic significance of heat shock proteins 27 and 70 in patients with squamous cell carcinoma of the esophagus. Cancer. 1999;85:1649-57.

28. Nakajima M, Kuwano H, Miyazaki T, Masuda N, Kato H. Significant correlation between expression of heat shock proteins 27,70 and lymphocyte infiltration in esophageal squamous cell carcinoma. Cancer Lett. 2002;178:99-106.

29. Yokomine K, Nakatsura T, Senju S, Nakagata N, Minohara M, Kira J, et al. Regression of intestinal adenomas by vaccination with heat shock protein 105-pulsed bone marrow-derived dendritic cells in Apc(Min/+) mice. Cancer Sci. 2007;98:1930-5.

\section{Acknowledgement}

Hereby, the financial support of the Research Deputy of Mashhad University of Medical Sciences is appreciated. 